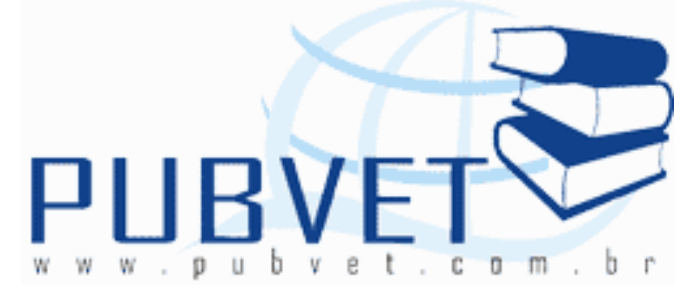

PUBVET, Publicações em Medicina Veterinária e Zootecnia.

Disponível em: <https://doi.org/10.31533/pubvet.v02n11a397>.

\title{
Viroses emergentes e reemergentes entre primatas não-humanos e humanos
}

\section{Rachel Siqueira de Queiroz Simões Marins}

Médica Veterinária, Mestre em Produção Animal e Doutora em Ciência Animal UENF.

\section{Introdução}

A emergência e reemergência de doenças virais são complexas. Muitas vezes não é necessário que novas infecções virais sejam causadas por novos vírus, mas sim por uma variante de um vírus já isolado, outras vezes podem ocorrer à adaptação do vírus infectando novos hospedeiros ou a introdução de infecções entre diferentes espécies. As epidemias emergentes são fruto do tráfego de microorganismos no qual um agente infeccioso pode ser transmitido de animais para seres humanos ou até mesmo disseminarem-se em novas populações (Santos, 2002).

Variações no genoma viral e recombinação gênica durante a sua replicação são alguns dos mecanismos utilizados na evolução dos vírus para o avanço das doenças virais, algumas ainda não conhecidas (Schatzmayr, 2001). 
A definição do termo virose emergente refere-se à ocorrência de novos casos dentre grupos ou populações num período recente de até duas últimas décadas ou a tendência de incidir num futuro próximo. O termo virose reemergente é atribuído à enfermidade que estava supostamente controlada e ressurgi causando novas epidemias (Santos, 2002).

Outro mecanismo envolvido no ressurgimento de doenças virais que haviam sido aparentemente controladas, é o processo das alterações genéticas desencadeando novas cepas virais mais virulentas e patogênicas, além é claro da proximidade dos seres humanos com os animais silvestres. Muitas doenças virais humanas têm sido reportadas em primatas e pouco se sabe sobre a história natural das infecções virais em populações de primatas neotropicais de vida livre (Diniz, 1997). O início da história natural das doenças associado aos primeiros contatos do homem com os primatas, remonta há 2.500 anos a.c, no Antigo Egito quando naquela época os reis criavam babuínos em cativeiros (Nunes \& Catão-Dias, 2007). Já no século XX, o interesse pelos macacos era destinado à comercialização desses animais para pets exóticos e para laboratórios de pesquisa. No final da década de 60, os Estados Unidos importaram mais de 140.000 macacos de diferentes espécies. Ainda há poucos dados sobre as espécies do gênero Cercopithecus enquanto a espécie mais estudada dentre os primatas de cativeiro é o macaco Rhesus (Macaca mulata) (Nunes \& Catão- Dias, 2007).

Atualmente, procedimentos operacionais tem se voltado para a vigilância de epizootias na pesquisa dos primatas não-humanos (PNH) como indicadores de saúde pública. Amostras biológicas de sangue, soro, fezes, pêlos e swabs são colhidos para investigar o perfil sanitário das colônias desses animais. $\mathrm{Na}$ Ásia é comum certas tribos irem à caça dos macacos como fonte de alimento, a presença desses animais em mercados livres, apresentações nas ruas, nos zoológicos e a presença de símios em domićlios, onde os macacos são tratados como animais de estimação são grandes fontes de disseminação do vírus entre o homem e o macaco, e vice-versa. 
Essa estreita relação remete principalmente pelo risco de mutação viral em romper barreiras entre as diversas espécies nos mais diferentes nichos ecológicos o que favorece a ocorrência de novas doenças zoonóticas (JonesEngel \& Engel, 2006). À exemplo de Bali, na Indonésia, cerca de seis pessoas de um total de mil ao visitar os templos de primatas para adoração religiosa se infectam com o vírus espumoso símio (SFV) por meio de mordidas transmitindo o vírus para o homem, presente até então apenas nos primatas não-humanos (Jones-Engel \& Engel, 2006). Há ainda a comercialização internacional de carnes de chimpanzés e gorilas vendidos ilegalmente para países da América do Norte e Europa Ocidental agravando as condições zoonóticas e propiciando a proliferação viral (Jones-Engel \& Engel, 2006).

Os primatas integram o grupo de animais de laboratório atuando como modelo biológico na pesquisa de doenças infecciosas no campo da oncologia, imunologia, genética entre outras pesquisas aplicadas na área de vigilância epidemiológica. Contudo, a importação desses animais visando à pesquisa clínica pode também trazer novos agentes até então desconhecidos, como ocorreu com o grupo de filovírus pertencentes à família Filoviridae. Essas viroses constituem um agravo à saúde pública nas áreas urbanas e rurais. Segundo dados da Organização Mundial de Saúde, entre as viroses emergentes destacam-se as febres hemorrágicas, vírus do Nilo Ocidental (West Nile Virus), Hantaviroses e Síndrome respiratória aguda grave severa (SARS). Esta última teve como marco de sua epidemia a Ásia, em 2003, quando espalhou-se para mais de 20 países nos continentes africanos, europeus e asiáticos. A seguir nos deteremos apenas nas viroses que acometem principalmente os primatas não-humanos e sua transmissão interespécies. Espera-se que este artigo retrate algumas viroses emergentes e reemergentes de suma importância para a Saúde Pública no campo da virologia humana e animal. 


\section{Febres Hemorrágicas}

\section{Marbug e Ebola vírus}

Em laboratórios na Alemanha após manipulação com macacos importados de Uganda, na África, dos 31 funcionários e pesquisadores que apresentaram casos de febre hemorrágica, oito morreram. A partir da coleta e análise de espécimes clínicos, deu-se origem a um novo vírus, chamado Marbug vírus. Nove anos mais tarde, ocorreram duas epidemias de febre hemorrágica responsáveis por mais de 550 casos e 430 mortes. Dessa vez, isolou-se um vírus morfologicamente idêntico, mas antigeneticamente distinto daquele vírus isolado anteriormente. A esse novo vírus denominou-se Ebola. Desde então novos subtipos vem sendo identificados de acordo com sua localização, sendo eles: Ebola Zaire, Ebola Sudão e Ebola Reston (Schatzmayr, 2001). Os três tipos possuem diferenças sorológicas e apresentam diferentes seqüências de bases no genoma RNA, entretanto apresentam similaridade filogenética com os paramixovírus (caxumba, sarampo e parainfluenza) e rabdovírus (raiva) (Murphy, 1999; Fields, 2001).

Considerada a maior epidemia Africana, principalmente no Zaire e Sudão em 1976, o Marbug e Ebola vírus vem fazendo vítimas não só no continente africano, como também, o vírus reapareceu em 1992, na Itália e em 1996, no Texas, Estados Unidos. Em outubro de 2004, foram registradas 156 mortes causadas pelo Marbug na Angola. Diversos animais experimentais têm sido estudados, inclusive várias espécies de macacos tais como: Rhesus (Macaca mulatta), Cynomolgus (Macaca fascicularis), Macacos verdes africanos (Cercopithecus aethiops) e Babuínos (Papio spp.). Até o momento, não há evidências de latência ou infecções persistentes do filovírus nos animais experimentais.

Responsável por uma taxa de mortalidade entre $70 \%$ a $90 \%$, o Ebola vírus, está classificado no nível quatro de patogenicidade, sendo superior ao HIV, segundo normas de biossegurança. Tendo em vista a alta patogenicidade 
viral, somente laboratórios voltados para a área da pesquisa científica e procedimentos diagnósticos, são permitidos o manuseio e a posse desses vírus regulado pelos órgãos governamentais. Além das duas zoonoses virais hemorrágicas, a febre amarela também é um risco em animais silvestres capturados, tendo como diagnóstico diferencial a febre hemorrágica dos símios, altamente contagiosa entre os primatas africanos e, fatal para as espécies asiáticas (Murphy, 1999; Fields, 2001; Merck, 2008).

\section{Febre amarela}

Ao contrário dos que muito pensam, os macacos funcionam como "sentinelas" da febre amarela silvestre, alertando as autoridades para a vigilância enzoótica, principalmente nas regiões tropicais da América do Sul, América Central e África, pois não propagam o vírus e sim são os primeiros a serem infectados antes dos homens. Entre as espécies de primatas mais susceptíveis destacam-se: Macaca sp., Papio sp., Cerocebus sp., Pan sp., Erythrocebus sp., e Cercopithecus sp. (Nunes \& Catão-Dias, 2007).

Segundo dados atuais do Centro de proteção de primatas brasileiros, o verdadeiro transmissor da doença para os primatas e seres humanos são os mosquitos, que atuam como vetores reservatórios do vírus e, uma vez infectados, permanecem por toda vida. O vírus da febre amarela é um flavivírus pertencente à família Flaviviridae e é considerado um arbovírus, isto é, vírus transmitido por artrópodes (arthropod borne virus). No ciclo urbano, o mosquito Aedes aegypti é o transmissor na área urbana, enquanto no ciclo silvestre os mosquitos dos gêneros Haemagogus e Sabethes são os mais importantes na América Latina, e no Brasil se destaca o mosquito Haemagogus janthinomys. No Brasil, entre 1980 e 2004 foram confirmados 662 casos de febre amarela silvestre em humanos ocorrendo mais de $50 \%$ de mortalidade. No início de 2008, ocorreram 19 casos de febre amarela em humanos na região do Centro-Oeste do Brasil, dos quais 10 morreram. 


\section{Retrovírus}

Dentre as viroses emergentes pesquisadas em primatas de vida livre encontra-se o Simian Immunodeficiency virus - SIV, também conhecido como síndrome da imunodeficiência em símios, presente na população de primatas do velho mundo (Khabbaz et al., 1994; Diniz, 1997). Da mesma família dos retrovírus, o SIV são lentiviroses de primatas não-humanos, relacionados morfologicamente e geneticamente com o vírus da imunodeficiência humana (Human immunodeficiency virus type 1 and 2 - HIV-1 e HIV-2), conhecido comumente como a Síndrome da Imunodeficiência Humana (Human acquired immunodeficiency syndrome - AIDS).

Pelos dados disponíveis, estudos retrospectivos apontam para a infecção do HIV-1 em primatas sob condições naturais e acredita-se que caçadores africanos de primatas se infectaram com o SIV ao ingerir a carne desses animais dando início a AIDS (Jones-Engel \& Engel, 2006). Evidências moleculares sugerem que o HIV-2 apresenta estreita relação com o SIV de macacos de cativeiro. Pesquisadores e técnicos de laboratório apresentaram anticorpos reativos para HIV-2 e SIV após exposição percutânea com sangue de macacos experimentalmente infectados com o SIV, confirmando que é possível a infecção dos primatas não-humanos em humanos (Khabbaz et al., 1994).

As doenças virais linfoproliferativas humanas, o HTLV-1 e 2 (Human T lymphotropic virus type 1 and 2) juntos com o simian vírus (STLV-1 e 2) pertencem as viroses linfoproliferativas $\mathrm{T}$ no grupo dos primatas. Mundialmente, o HTLV-1 infecta aproximadamente 20 milhões de pessoas e o STLV-1 é endêmico nos primatas de espécies da Ásia e da África. Entretanto, existe uma alta homologia entre esses dois vírus, sendo que a maioria dos subtipos do HTLV-1 surge da transmissão interespécies entre macacos e homens (Mahieux \& Gessain, 2008). Outros retrovírus podem causar a imunodeficiência predispondo a um complexo de doenças infecciosas como a 
infeç̧ão por citomegalovírus em colônias de macacos verdes africanos (Cercopithecus aethiops) e cercocebus (Cercocebys atys). Por sua vez, o retrovírus tipo $C$ resulta em infecção principalmente nos macacos do Velho Mundo. De modo geral, existe uma grande susceptibilidade de transmissão dos vírus e a disseminação entre os primatas é feita pelo contato direto ou indireto pelo sangue infectado e outros fluidos corporais, como também da fêmea para a prole (Merck, 2008).

Novas pesquisas envolvendo espécimes biológicos de humanos da África que tiveram contato com sangue e fluidos corporais de primatas não-humanos revelaram novas retroviroses ainda não descritas (Wolfe et al., 2005). Acredita-se que as novas viroses humanas linfoproliferativas - T do tipo 3 e 4 (Human T lymphotropic virus type 3 and type 4 - HTLV-3 e HTLV-4) foram contraídas pelos homens ao caçarem os primatas e se infectaram por meio de sinais de mordeduras e arranhaduras. Foi demonstrada a homologia entre o HTLV-3 e STLV-3 em homens assintomáticos no Sul de Camarões, na África Central comprovando a similaridade genética do HTLV-3 com o simian vírus (Mahieux \& Gessain, 2008). Por sua vez, o HTLV-4 é distinto de todos os vírus símios conhecidos (Wolfe et al., 2005).

\section{Hepatite vírus}

No grupo das hepatites, o vírus da hepatite A (HAV) ocorre naturalmente nos chimpanzés (Pan troglodytes) e nos sagüis da família Callitrichidae que são sensíveis ao tipo A. Também conhecida como hepatite de curto período de incubação, é responsável pela transmissão oro-fecal, podendo os animais infectados eliminar o vírus através das fezes contaminadas. A hepatite B e A-B negativa são contraídas pela transmissão por transfusão ou agulhas não esterilizadas. 
O vírus da hepatite A (HAV) pertence aos picornavírus e é responsável por infectar espécies africanas, asiáticas e primatas neotropicais. Foi detectada a presença de anticorpos contra o vírus da hepatite A (HAV) em quatro dos 12 primatas de vida livre em babuínos da África do Sul e dois macacos-da-noite foram positivos dos 145 pesquisados. Acredita-se por evidências moleculares que o ciclo silvestre do HAV ou HAV-like vírus esteja presente em primatas não-humanos em diferentes tipos distintos do vírus. Diversas espécies de primatas são susceptíveis à infecção experimental, como por exemplo: chimpanzé, mico e macaco-da-noite. O vírus foi identificado por testes sorológicos em macacos de cativeiro como rhesus, cynomolgus e babuínos. Os vírus da hepatite $A$ e $B$ têm sido identificados em gorilas e orangotangos e presente em grupo de chimpanzés nascidos em cativeiro (Nunes \& Catão-Dias, 2007).

\section{Viroses dermotrópicas}

\section{Herpesvírus}

Os herpesvírus são conhecidos pelas infecções latentes ou subclínicas nos hospedeiros reservatórios e tem sido relatado em primatas do Velho Mundo. Em geral, os primatas são transmissores do Cercopithecine herpesvírus tipo 1 também conhecido como herpesvírus simae tipo B provocando um quadro clínico de conjuntivite e vesículas orais em Macaca $s p$. , e um quadro neurológico de encefalomielite ou encefalite fatal em humanos. O macaco Rhesus (Macaca mulata) particularmente atua como reservatório e não manifesta sintomatologia clínica. Os casos de fatalidades humanas decorrentes das doenças virais em primatas não humanos são derivadas da proximidade e da exposição com esses animais prevalecendo o nível de biossegurança evitando o contato direto e indireto com os fluidos corpóreos e secreções dos primatas infectados (Diniz, 1997; Merck, 2008). 
Principalmente nos macacos-de-cheiro (Saimiri sciureus), o saimiriine herpesvírus tipo 1 também chamado de Herpesvírus tamarindus ou Herpes T causa estomatite e úlceras herpéticas, entretanto podem ocorrer a transmissão natural de herpesvirose $T$ para macacos-da-noite (Aotus sp.), macaco aranha (Ateles geoffroyi) e micos comumente fatal nestas espécies. Certos primatas como os macacos-da-noite (Aotus sp.), os gibões da família Hylobatidae e os tupaias (Tupaia glis) são susceptíveis às infecções de herpesvírus simplex tipo 1 do homem provocando lesões ulcerativas, febres, prostração nos primatas podendo levar esses animais a óbito (Diniz, 1997; Merck, 2008).

\section{Simian vírus}

Os mesmos genes supressores, p53 e proteína do retinoblastoma (pRb), são compartilhados com outros vírus tumorais DNA, como o Simian vírus (SV40). Similar à ação do papilomavírus, possuem oncoproteínas que interagem com esses genes supressores tumorais $e$ interrompem os checkpoints mitóticos mediando a oncogênese celular (Thompson et al., 1997). Este vírus tumorgênico pertence à mesma família Papovaviridae, na qual antigamente o papilomavírus era classificado. O SV40 foi descrito pela primeira vez em 1960 por Sweet \& Hilleman, ao detectarem o efeito citopático viral pela formação de vacúolos citoplasmáticos em culturas de células renais de primatas das espécies Rhesus e Cynomolgus como portadores assintomáticos da infecção (Wittmann, 1999).

\section{Papilomavírus}

São escassos os estudos epidemiológicos sobre a papilomatose em animais silvestres, em particular os primatas não-humanos. Entretanto, diferentes espécies de papilomavírus têm sido identificadas nestes animais e encontram-se disponíveis no banco de dados do Comitê Internacional de 
Taxionomia Viral (ICTV). Algumas destas espécies de papilomavírus em animais silvestres já estão classificadas entre os diferentes gêneros da família Papillomaviridae e entre os cinco supergrupos (A-E) do maior nível de diversidade da árvore filogenética. Outras destas espécies do vírus do papiloma em animais silvestres, ainda não estão devidamente classificadas, mas já estão consideradas para a classificação oficial pelo ICTV.

Entre as espécies de papilomavírus, atualmente encontram-se espécies no supergrupo A classificada no gênero Alphapapillomavirus que acometem o trato genital dos humanos (Human papillomavirus - HPV) e causam a papilomatose em primatas, como o macaco Rhesus (Rhesus monkey papillomavirus - RhPV) e o chimpanzé Pigmeu (Pygmy chimpanzee papillomavirus - PCPV-1 e PCPV-1C), embora exista também algumas espécies ainda não classificadas em gênero como o caso do macaco Colobus (Colobus monkey papillomavirus - CgPV).

No maior grau de homologia interespécies do grupo dos papilomavírus (PV), o potencial oncogênico do Rhesus monkey papillomavirus tipo 1 (RhPV-1) é sugerido em diversos animais infectados, pela presença de vários níveis de neoplasia, incluindo o câncer das células escamosas do colo uterino (Ostrow et al., 1990). Como resultado de pesquisas que utilizaram amostras genitais de macaco Rhesus (Macaca mulatta) e macaco da cauda longa (Macaca fascicularis), 12 amplicons distintos de RhPV foram detectados, o que corrobora a hipótese do macaco Rhesus ser o hospedeiro das papilomatoses com uma diversidade similar aos tipos virais de humanos (Chan et al., 1997). $\mathrm{Na}$ árvore filogenética, todos os 12 diferentes amplicons de RhPVs têm sido previamente descritos como do RhPV do tipo 1. Estes novos amplicons são considerados membros do supergrupo de HPV genital e formam três ramos menores, distintos dos 11 ramos formados pelos HPVs genitais (Chan et al., 1997). O PV do tipo 1 de Rhesus (RhPV-1) é similar aos HPVs oncogênicos, tais como HPV-16 ou HPV-18 (Ostrow et al., 1990). Em conexão, amostras de PVs de primatas mostraram-se intimamente relacionadas com HPVs cutâneos 
(HPV-1, HPV-41, HPV-63), HPVs genitais e HPV-epidermodisplasia verruciforme (Chan et al., 1997).

A identificação de dois PVs do macaco Colubus (CgPV-1 e CgPV-2), como representantes típicos de verrugas genitais, bem como da epidermodisplasia verruciforme (EV-PVs), mostrou que eventos de ramificação da árvore filogenética dos PV podem também pré-supor ramos distantes de linhagens de diferentes hospedeiros (Chan et al., 1997). Ostrow et al., (1990)., Chan et al., (1997) e Antonsson \& Hansson, (2002) pesquisaram os primatas não-humanos do Velho Mundo correlacionando com achados da infecção pelo PV, entretanto há ainda poucos estudos nestas espécies.

Um novo vírus do papiloma amplificado foi identificado, MfPV-a, na espécie Macaca fascicularis, pertencente ao mesmo gênero do macaco Rhesus (Macaca mulatta). O MfPV-a pode ter uma relação restrita com tipos de RhPVs (Chan et al., 1997). Parece que a evolução das linhagens dos primatas conduzida pelo gênero Macaca e as barreiras de transmissão pelo HPV, resulta em uma evolução viral estritamente relacionada com o hospedeiro (Chan et al., 1997).

Considerar o relacionamento entre alguns HPVs e PVs de primatas não-humanos como sendo o resultado de uma transmissão interespécies ativa homem-macaco, com referência particular ao Pygmy chimpanzee papillomavirus (PCPV-1) e, ao grupo de HPV-6, HPV-11 e HPV-13, tem proposto que a transmissão interespécies entre primatas não-humanos e humanos pode ser viável (Chan et al., 1997).

Estudos complementares têm demonstrado a importância do aspecto biológico na ocorrência de infecções pelo RhPV-1 em macacos Rhesus (fêmeas sexualmente ativas e machos) infectados pelo RhPV-1 que desenvolveram tumores malignos (Ostrow et al., 1990). Neste contexto, isolou-se e caracterizou-se um tipo de PV oriundo de Rhesus que parece ser um modelo útil para o estudo da transmissão sexual e da oncogenicidade da infecção pelo 
PV na genitália de macacos (Ostrow et al., 1990). Com isso, estima-se encontrar um modelo animal de papilomavírus com base em protocolos experimentais e emprego de amostras genitais de macacos Rhesus e macacos de cauda longa para a pesquisa de doenças causadas pelo HPV (Chan et al., 1997).

Em macacos, achados clínicos e patológicos sugerem infecção positiva contendo DNA RhPV-1 integrado ao DNA da célula tumoral, confirmado pelas técnicas de hibridização. Evidências histopatológicas da infecção pelo RhPV-1 a partir de biópsias cervicais mostraram um aumento proporcional das células basais e parabasais, a presença de quoilócitos e células ocasionais com núcleo atípico ampliado. Outros achados característicos do PV também estavam associados à perda de maturação, aumento da atividade mitótica e, ocasionalmente, notou-se carcinoma das células escamosas bem diferenciado e focalmente invasivo. No exame post-mortem, é possível detectar carcinoma adenoescamoso no endocérvix (Ostrow et al., 1990).

Nova estratégia molecular utilizada na tentativa de obter uma intensificação do sinal produzido pelas amostras amplificadas pela técnica de reação em cadeia de polimerase (Polymerase chain reaction - PCR) foi empregada como o Nested PCR ou Semi-Nested PCR (Mello, 2005). Contudo, a construção de um novo par de iniciadores baseados na identidade da seqüência de nucleotídeos a partir do gene L1, maior proteína do capsídeo na montagem da partícula viral infectante, e somando-se ainda o desenho de um novo par de oligonucleotídeos tipo-específico para os novos prováveis tipos de PVs detectados, tem gerado maior êxito na análise dos estudos moleculares (Antonsson \& Mc Millan, 2006).

No Brasil, a primeira investigação do estudo da infecção latente em símios foi realizada em 2005, pelo pesquisador Mello, coordenado pela Dra. Luísa Villa, ao pesquisar em amostras de swabs de pênis, vagina e colo uterino de 306 primatas sem sinais clínicos de lesão proveniente de 16 espécies de 
primatas de cativeiro. Os resultados da pesquisa apontam que, dos 154 espécimes analisados, apenas em sete amostras da espécie Alouatta caraya foi possível a detecção da presença de DNA do papilomavírus totalizando 4,54\% das amostras analisadas por PCR. Em 2008, nova pesquisa sobre a investigação da infecção clínica e latente com espécies bem diversificadas de animais domésticos e silvestres foi realizada a partir de espécimes biológicos de sangue de animais sem sinais clínicos da doença e amostras de lesões cutâneas obtidas de biópsias epiteliais (dados do autor).

\section{Outras viroses}

Viroses respiratórias como os paramixovírus, influenzavírus e o vírus respiratório sincicial apresentam alta morbidade entre os primatas e assumem um papel clínico altamente contagioso. Outras viroses como o vírus da varicela símia (SVV) acomete preferencialmente as espécies Pan sp., Pango sp., e Gorila $s p$. , e é antigeneticamente relacionada com o herpes zoster humano e com o adenovírus específico para as espécies Macaca sp., e Papio sp. (Nunes \& Catão-Dias, 2007).

Novos estudos apontam para a pesquisa do vírus da encefalite Saint Louis (SLEV), um arbovírus da família Flaviviridae transmitida principalmente pelo mosquito do gênero Culex que afeta acidentalmente o homem e outros mamíferos. No Brasil, a doença foi identificada desde a década de 70 e reapareceu no interior de São Paulo em 2004 quando foi diagnosticada por isolamento viral. O vírus foi detectado nas espécies de primatas Alouatta caraya, Cebus negritus e Cebus cay. Nesta última também foi comprovada por testes moleculares de transcrição reversa e Nested PCR, a ocorrência de outro vírus, o bornavírus responsável pela doença de Borna (Borna disease virus $\mathrm{BDV}$ ), que atinge o homem provocando um quadro clínico de doença neuropsiquiátrica (Svoboda, 2007). No Brasil, algumas cepas virais do BDV já 
foram identificadas nos Estados do Rio de Janeiro, São Paulo, Minas Gerais, Pernambuco, Bahia e Pará.

Em 1958, na Suécia, foi isolado um novo vírus de macacos Cynomolgus denominado Orthopoxvirus, que inclui a varíola e a vaccínia. No Zaire, entre a década de 70 até o final dos anos 80, foram registrados novos casos de infecções humanas com o novo vírus identificado (Schatzmayr, 2001). O vírus da varíola do macaco está imunologicamente relacionado ao da varíola humana. Estudos investigam a possibilidade do orangotango ser susceptível assim como outras espécies de primatas como o gibão, rhesus, saimiri e cercopithecídeos (Diniz, 1997).

\section{Conclusão}

Algumas medidas de prevenção e profilaxia devem ser adotadas por tratadores, técnicos e especialistas no contato e manipulação com os animais selvagens como o uso de luvas, óculos de proteção, máscaras e vestimentas apropriadas. Esses procedimentos evitam o contato físico por meio de mordidas, arranhões, secreções e excreções, dentre outras formas de contágio, além da implantação de novas normas nas instalações das colônias a fim de propiciar um habitat natural e seguro para os animais.

Outras medidas de controle também devem ser preconizadas na prevenção de viroses zoonóticas como a vigilância epidemiológica, pesquisa aplicada, investimentos em infra-estrutura com laboratórios equipados e controle de vetores (Schatzmayr, 2001). Contudo, caso haja a interrupção na aplicação prática dessas medidas, o agente viral pode permanecer no ambiente em seus hospedeiros reservatórios e reemergir em caso de falha das medidas empregadas na saúde pública (Santos, 2002).

A proposta do presente artigo é alertar as autoridades para uma visão mais humanitária e prevenir novos surtos e epidemias que comprometem e 
põe em risco, principalmente, a camada da população sem infra-estrutura e condições sanitárias básicas. A conscientização deve vir primeiro daqueles que governam e competem as ações públicas para tentarem minimizar focos de possíveis infecções virais antes de alastrarem-se. Do mesmo modo que cabe ao profissional qualificado instruir sobre o perigo em oferecer alimentos inadequados aos animais de cativeiro e os de vida livre, e informar os riscos que são submetidos ao agir de maneira errônea expondo-se ao contato com os animais silvestres, incluindo os primatas não-humanos, de forma a propiciar o surgimento e ressurgimento de patógenos zoonóticos. Com este trabalho, espera-se ter contribuído com a importância que as doenças virais desempenham no âmbito da saúde pública.

\section{Referências Bibliográficas}

ANTONSSON, A., HANSSON, B. G (2002) Healthy skin of many animal species harbors papillomaviruses which are closely related to their human counterparts. Journal of Virology, 76 (24):12537-12542.

ANTONSSON A., Mc MILLAN, N.A.J (2006) Papillomavirus in healthy skin of Australian animals. Journal of General Virology, 87: 3195 - 3200.

CHAN, S.Y., BERNARD, H.U., RATTERREE, M., BIRKEBAK, T.A., FARAS, A.J., OSTROW, R (1997) Genomic diversity and evolution of papillomaviruses in Rhesus Monkeys. Journal of Virology, 71(7): 4938-4943.

DINIZ, L. S.M (1997) Primatas em cativeiro: Manejo e problemas veterinários, São Paulo: Icone Editora, 196p.

INTERNATIONAL COMMITEE ON TAXONOMY OF VIRUSES - ICTV (2008) ICTV approved Virus Orders, Families and Genera; <http://www.ncbi.nlm.nih.gov/ICTVdb/Ictv/index.htm>

JONES-ENGEL, L., ENGEL, G. A (2006) Disease risk analysis: a paradigm for using healthbased to inform primate conservation and public health. American Journal of Primatology, 68 (9):851-854.

FIELDS, B.N (2001) Fileds Virology (CD-ROM). 4. Ed., vol.2. New York: Lippincott Williams \& Wilkins Publishers: Philadelphia. 
KHABBAZ, R. F., HENEINE, W., GEORGE, R., PAREKH, B., ROWE, T., WOODS, T., SWITZER, W .M., MC CLURE, H.M., MURPHY-CORB, M., FOLKS, T.M (1994) Infection of a Laboratory Worker with Simian Immunodeficiency virus. The New England Journal of Medicine, 330:172-177.

MAHIEUX, R., GESSAIN, A (2008) The human HTLV-3 and HTLV-4 retroviruses: new members of the HTLV family. Pathologie and Biologie, in press.

MELLO, W, A (2005) Investigação de papilomavírus em primatas não humanos do novo mundo: ocorrência e caracterização molecular. Tese (Doutorado em Biologia de Agentes Infecciosos e Parasitários) - Belém - PA, Universidade Federal do Pará - UFPA, 115 p.

MERCK (2008) Doenças Virais. In: Manual Merck de Veterinária, São Paulo: Editora Roca, 9.ed.,1334p.

MURPHY, F.A (1999) Veterinary Virology. Ed.3. American Press: San Diego.

NUNES, A. L. V., CATÃO-DIAS, J.L (2007) Primates - Primatas do Velho Mundo (Babuíno, Mandril, Chimpanzé, Orangotango). In: Cubas, Z. S., Catão Dias, J. L., Silva, J. C. R (Eds.) Tratado de animais selvagens de Medicina Veterinária, São Paulo: Editora Roca, p. 378-401.

OSTROW, R.S., Mc GLENNEN, R.C., SHAVER, M.K., KLOSTER, B.E., HOUSER, D., FARAS, A.J. (1990) A Rhesus monkey model for sexual transmission of a papillomavirus isolated from a squamous cell carcinoma. Proceedings of National Academy Sciences, 87: 8170-8174.

SANTOS, N. S.O (2002) Emergência e Reemergência de Viroses. In: Santos, N. S. O., Romanos, M. T. V., Wigg, M.D (Eds.) Introdução à Virologia Humana., Rio de Janeiro: Guanabara Koogan, p. 235-238.

SCHATZMAYR, H.G (2001) Emerging and reemerging viral diseases. Caderno de Saúde Pública, 17: 209-213.

SVOBODA, W. H (2007) Vigilância de epizootias em primatas não-humanos (PNH) como instrumento de monitoramento de arboviroses e outras viroses de interesse em saúde pública. Tese (Doutorado em Ciência Animal) - Londrina -PR, Universidade Estadual de Londrina - UEL.

THOMPSON, D.A., BELINSKY, G., CHANG, T, H-T., JONES, D, L., SCHLEGEL, R., MUNGER, K (1997). The human papillomavirus -16 E6 oncoprotein decreases the vigilance of mitotic checkpoints. Oncogene, 15: 3025 - 3035.

WITTMANN, W (1999) Infecções por papovavírus. In: Beer, J (ed.) Doenças Infecciosas em Animais Domésticos. São Paulo: Roca, p. 256 - 261.

WOLFE, N.D., HENEINE, W., CARR, J.K., GARCIA, A.D., SHANMUGAN, V., TAMOUTE, U., TORIMIRO, J.N., PROSSER, A.T., Le BRETON, M., MPOUDI-NGOLE, E., MC CUTCHAN, F.E., BIRX, D.L., FOLKS, T.M., BURKE, D.S., SWITZER, W.M (2005) Emergence of unique primate Tlymphotropic viruses among Central African bushmeat hunters. Proceeding National Academy of Sciences, 102 (22): 7994-7999. 